\title{
A low-cost media for leptolyngbya (cyanobacteria) strain growth isolated from indonesia as a potential biofuel feedstock
}

\author{
Nurul Rakhmayanti ${ }^{1}$, Alinda Nurmarina $^{1}$, Nining Betawati Prihantini ${ }^{1,{ }^{*}}$, Sri Handayani ${ }^{2}$ and Nasruddin $^{3}$ \\ ${ }^{1}$ Department of Biology, Faculty of Mathematics and Natural Sciences, Kampus UI 16424, Depok \\ ${ }^{2}$ Department of Chemistry, Faculty of Mathematics and Natural Sciences, Kampus UI 16424, Depok \\ ${ }^{3}$ Department of Mechanical Engineering, Faculty of Engineering, Kampus UI 16424, Depok
}

\begin{abstract}
The study of a low cost media for Leptolyngbya growth had been done. Commercial NPK fertilizer was one of the low cost media that commonly used for microalgae growth. The objective of this study aimed to determine the best concentration of commercial NPK fertilizer for Leptolyngbya NBP-7A growth as a potential biofuel feedstock. Leptolyngbya NBP-7A was isolated from Cisolok hot spring, located in Indonesia. In this study, Leptolyngbya NBP-7A was grown in commercial NPK fertilizer with concentration 80 ppm, 240 ppm, and in BBM (Bold Basal's Medium), BBM+NPK 80 ppm as a control. This strain was incubated on $35^{\circ} \mathrm{C}$. Observation were made approximately 14 days with 2 sampling for each media. The average of wet weight Leptolyngbya NBP-7A after $14^{\text {th }}$ day observation, was obtained at NPK 80 ppm was $5 \mathrm{mg} / \mathrm{L}$, NPK 240 ppm was $4.1 \mathrm{mg} / \mathrm{L}, \mathrm{BBM}$ was $19.75 \mathrm{mg} / \mathrm{L}$, and BBM+NPK $80 \mathrm{ppm}$ was $14.65 \mathrm{mg} / \mathrm{L}$ ). The results of 14 days observation showed that the best concentration NPK culture media for growing Leptolyngbya NBP-7A was in BBM + NPK 80 ppm. This study showed that commercial NPK fertilizer could be used for Leptolyngbya NBP-7A growth as a potential biofuel feedstock.
\end{abstract}

\section{Introduction}

Microalgae have the potential as used for biofuel production [1]. Despite that, microalgae has several advantages for using them as biofuel production. The advantages of this organisms such as growth faster, easy to be manipulated and used $\mathrm{CO}_{2}$ as carbon source [2]. One of the microalgae that can be used as biofuel production is cyanobacteria.

Cyanobacteria can be found in soil, rocks and waters [3]. Another source where cyanobacteria can be found is hotspring [4]. Cisolok hotspring is the example of source whereas cyanobacteria can be found. Leptolyngbya is one genus of cyanobacteria that can be found in cisolok hotspring.

Leptolyngbya have filamentous as the form of the colony. Characteristic of these organisms have a thin filament with 0,5 to 3,5 wide with simple trichome, and some species have sheath [5]. Leptolyngbya can be found in environmental condition with $\mathrm{pH} 7$ to 8,5 [6].

Leptolyngbya can also have potential as used for biofuel production. It could be happened because Leptolyngbya has ability for production lipid as one of the raw material as used biofuel production [7]. High lipid production was supported by high biomass production. Biomass production depends on nutrients in growth media. Nutrients that have a plays role in biomass production were $\mathrm{N}$ (nitrogen), $\mathrm{P}$ (phosphorus), $\mathrm{K}$ (potassium) [8]. Those nutrients are available in growth media of cyanobacteria.
Many research for search a low cost media had been done. One of low cost media that could be used for microalgae is commercial fertilizer NPK [8]. Commercial fertilizer NPK has been used for cultivation of Scenedesmus sp and could produced high lipid contain $28.55 \%$ of biomass [10]. Unfortunately, this low cost media has not been yet attempted to grow Leptolyngbya NBP-7A. The aim of this study is to determine the best concentration of commercial NPK fertilizer for Leptolyngbya NBP-7A growth.

\section{Materials and Methods}

\subsection{Microorganisms and Growth Medium.}

The microorganisms which used in this study was cyanobacteria genus Leptolyngbya strain NBP-7A. Leptolyngbya NBP-7A was isolated from Cisolok hotspring. Those strains were grown in variants of growth medium. The growth medium consist of BBM and BBM added with NPK $80 \mathrm{ppm}$ as a control, NPK $80 \mathrm{ppm}$ and NPK $160 \mathrm{ppm}$. BBM was obtained by following the recipe. NPK growth media were obtained by dissolve the commercial fertilizer NPK GrowMore 20:20:20 in 1000 $\mathrm{mL}$ aquades. The concentration of growth media depends on how much commercial fertilizer NPK dissolve. For example, $80 \mathrm{ppm}$ was obtained by $80 \mathrm{mg}$ dissolve in 1000 $\mathrm{mL}$ aquades. BBM plus NPK was obtained by added

\footnotetext{
* Corresponding author: nining.prihantini@gmail.com
} 
BBM $1000 \mathrm{~mL}$ and dissolved NPK $80 \mathrm{mg}$, then homogenized with magnetic stirrer.

\subsection{Cyanobacteria cultivation in variants growth medium.}

The first step of cultivation cyanobacteria is inoculated 30 $\mathrm{mg}$ biomass of each strain into growth medium. Before cyanobacteria were inoculated into variant growth medium, amount $70 \mathrm{~mL}$ of growth medium were added into erlenmayer flask $100 \mathrm{~mL}$. The treatment of each growth media was repeated twice. The strain were incubated at temperature $35^{\circ} \mathrm{C}$.

\subsection{Measurement the weight of wet biomass Leptolyngbya NBP-7A}

Measurement of Leptolyngbya NBP-7A biomass were done in 14 days with 9 times of sampling. The sterile eppendorf tube $1.5 \mathrm{~mL}$ was measured at analytical measurement tool. Biomass of Leptolyngbya NBP-7A was taken aseptically with sterile micropipet amount of 1 $\mathrm{mL}$. Eppendorf tube with biomass inside was sentrifuged for 10 minute with $10.000 \mathrm{rpm}$. The supernatant was taken out and wet biomass weight was measured with analytical measurement tool. The growth curves was made by comparrison between wet biomass weight as the ordinate axis $\mathrm{Y}$ with observed time as absisca $\mathrm{X}$. The growth curves were made by Microsoft Excel.

\section{Result and Discussion}

The study of growth Leptolyngbya NBP-7A taken 14 days with 9 times of sampling. The result produced growth curve of Leptolyngbya NBP-7A in variant growth media. The growth curve of this study still imperfect, because Leptolyngbya NBP-7A was still adapted with the condition of variation growth media. It could be seen at the growth curve of Leptolyngbya NBP-7A produce the growth curve unstable. The age of inoculum that used in this study was 1 months old.

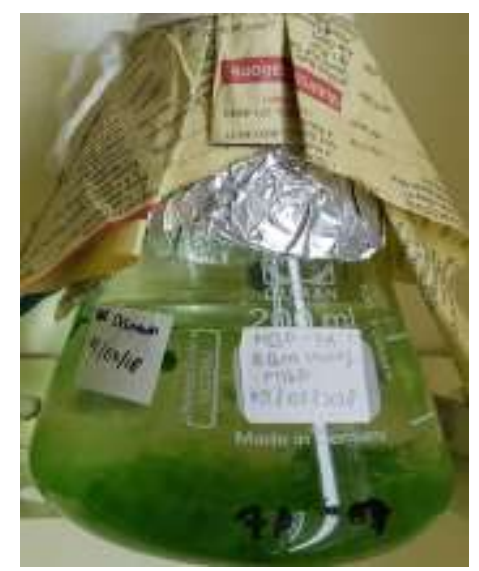

Fig. 1. Biomass Leptolyngbya NBP-7A in erlenmayer flask $200 \mathrm{~mL}$.
Macroscopic observation of Leptolyngbya were observed. Color appereance of Leptolyngbya based on Faber Castle standard color. Color appereance of Leptolyngbya NBP-7A was sea grass at day 0 (t0). Macroscopic observation of Leptolyngbya NBP-7A shown on Fig. 1.

The Average of wet weight biomass of Leptolyngbya NBP-7A shown on Table 3, while the growth curve of Leptolyngbya NBP-7A shown on Fig. 2. The growth curve of Leptolyngbya NBP-7A were made based on their wet weight of biomass.

Table 1. The Average of wet weight biomass of Leptolyngbya NBP-7A

\begin{tabular}{|r|r|r|r|r|}
\hline \multirow{2}{*}{ Time } & \multicolumn{5}{|c|}{ Wet weight (mg) } \\
\cline { 2 - 5 } & $\begin{array}{c}\text { NPK 80 } \\
\text { ppm }\end{array}$ & $\begin{array}{c}\text { NPK 160 } \\
\text { ppm }\end{array}$ & \multicolumn{1}{c|}{ BBM } & $\begin{array}{c}\text { BBM + NPK } \\
\text { 80 pm }\end{array}$ \\
\hline 0 & 30 & 30 & 30 & 30 \\
\hline 1 & 2.15 & 2 & 0.8 & 1.85 \\
\hline 2 & 3.45 & 8.3 & 2.8 & 5.6 \\
\hline 3 & 13.45 & 12.65 & 14.2 & 1.005 \\
\hline 4 & 7.05 & 8.55 & 6.65 & 5.65 \\
\hline 7 & 18.8 & 4.2 & 18.75 & 12.4 \\
\hline 8 & 12.25 & 6.15 & 6 & 13.85 \\
\hline 11 & 17.3 & 4.75 & 19 & 9.55 \\
\hline 12 & 14.1 & 11 & 1.59 & 25.65 \\
\hline 14 & 5 & 4.1 & 19.75 & 14.65 \\
\hline & & & & \\
\hline
\end{tabular}

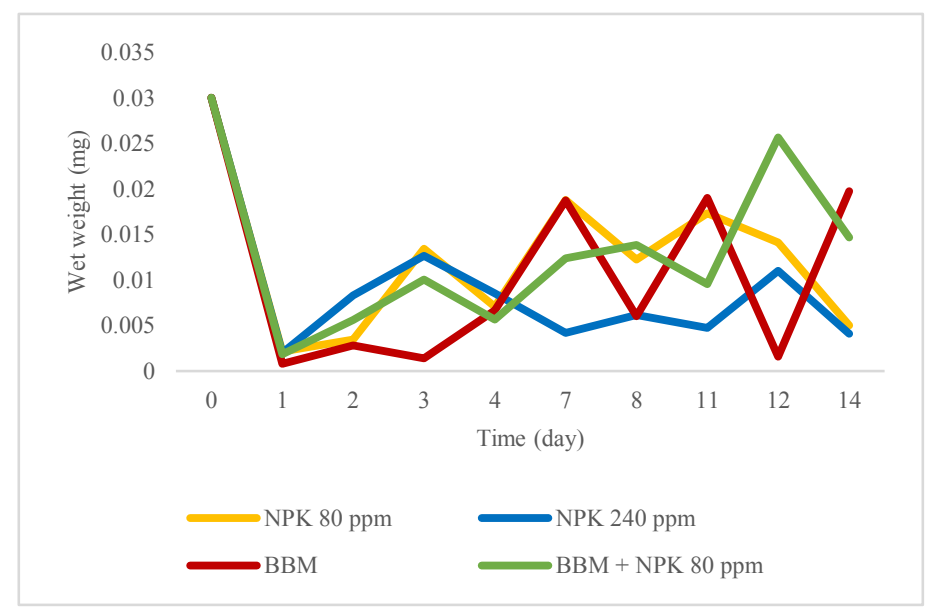

Fig. 2. The growth curve of Leptolyngbya NBP-7A

After $14^{\text {th }}$ day of incubation Leptolyngbya NBP-7A were able to grow in NPK growth media with concentration $80 \mathrm{ppm}$ and $160 \mathrm{ppm}$. Compared to Bold's Basal Medium (BBM) and BBM + NPK $80 \mathrm{ppm}$ as a control, Leptolyngbya NBP-7A has the lowest wet weight biomass at both concentration of NPK growth media. Wet weight of Leptolyngbya NBP-7A in 80 ppm NPK growth media was $5 \mathrm{mg}$, and $160 \mathrm{ppm}$ was $4.1 \mathrm{mg}$. 
The wet weight biomass of Leptolyngbya NBP-7A in all of growth media were rise from $0^{\text {th }}$ until $3^{\text {th }}$, except in $\mathrm{BBM}+\mathrm{NPK} 80 \mathrm{ppm}$. After $3^{\text {th }}$ day observation, the wet weight biomass of Leptolyngbya NBP-7A were decreased in all of growth media. At the day observation $7^{\text {th }}$, Leptolyngbya NBP-7A produced the growth curve unstable. It could be seen from the figure that Leptolyngbya NBP-7A produce wet weight biomass in all of growth media rise at $7^{\text {th }}$, then decreased at $8^{\text {th }}$ day, then rise again at $11^{\text {th }}$ day, and decreased at $14^{\text {th }}$ day of observation. It might be happened because Leptolyngbya NBP-7A still adapted with new environmental condition, especially the nutrient in growth media [10]. But, as we can see from the growth curve Leptolyngbya NBP-7A, the highest biomass production was in NPK $80 \mathrm{ppm}$ in $7^{\text {th }}$ day of observation. Based on the result in $7^{\text {th }}$ days of observation, we can harvest the biomass of Leptolyngbya NBP-7A in short time period.

Leptolyngbya NBP-7A were able to grow in a lowcost media using commercial fertilizer NPK. Concentration of commercial fertilizer NPK affected the grow of Leptolyngbya NBP-7A. From the result, it could be seen that Leptolyngbya NBP-7A was more adapted with concentration $80 \mathrm{ppm}$ than $240 \mathrm{ppm}$. It could be happened because the higher concentration of nitrogen contain in growth media of microalgae can caused toxic in microalgae. The higher concentration of nitrogen caused disruption of photosynthetic pigment formation [9]. The highest biomass production at the end of observation was in BBM + NPK $80 \mathrm{ppm}$. It could be happened because BBM + NPK 80 ppm was rich media. The macronutrient and micronutrient in BBM made Leptolyngbya NBP-7A produce more biomass production. Although the growth curve of Leptolyngbya NBP-7A in this study still unstable and need more day of observation, because Leptolyngbya NBP-7A still adapted with the growth media. The more biomass produced, the higher lipid content was produced and potentially could be used as biofuel feedstock.

\section{Conclusion}

Based on the observation of the $7^{\text {th }}$ day and the discussion that had been done, Leptolyngbya NBP-7A were able to grow in a low-cost media using commercial fertilizer NPK. The best growth media for Leptolyngbya NBP-7A $80 \mathrm{ppm}$. It could be seen from the result that Leptolyngbya NBP-7A produce the highest biomass production at $7^{\text {th }}$ day observation. As we can see from the result, we can harvest the biomass of Leptolyngbya NBP-7A in short period time. Furthermore, we can exchange the BBM with NPK fertilezer as growth media for Leptolyngbya NBP7A growth.

This work was fully funded by Hibah Publikasi International Terindeks untuk Tugas Akhir Mahasiswa (PITTA) 2018 to Nining Betawati Prihantini, grant no. 2288/UN2.R3.1/HKP.05.00/2018.

\section{References}

1. K. Y. Wong, Y. H. Ho, K. C. Ho, H. M. Leung, K. K. L. Yung. Growth medium screening for Chlorella vulgaris growth and lipid production, 6 (2017).

2. N. E. Nozzi, J. W. K. Oliver, S. Atsumi. Cyanobacterial as a platform for biofuel production, 1 (2013).

3. H. C. Bold, M. J. Wyne. Introduction to the algae. (Prentice-hall Inc, USA, 1978)

4. N. B. Prihantini. Polyphasic taxonomy of culturable cyanobacteria iasolated from hot springs in west java, Indonesia. (Departement of Biology FMIPA UI, Depok, 2015)

5. J. Komarek. Phenotype diversity of the diversity of the cyanobacterial genus Leptolyngbya in the maritime antartic, 3 (2007)

6. K. Olsson-Francis, A. E. Simpson. The effect of rock composition on cyanobacterial weathering of crystalline basalt and rhyolite, 10 (2012)

7. L. Giddings, D. J. Newman. Bioactive compounds from terrestrial extremophiles. (Springer, USA, 2017).

8. S. H. Ammar. Cultivation of microalgae Chlorella vulgaris in airlift photobioreactor for biomass production using commercial NPK nutrients, 12 (2015).

9. A. Mangaiyarkarasi, D. R. Geetha, M. Naveena. Optimization of fertilize based media for the cultivation of Scenedesmus species, 8 (2017).

10. M. Madigan, J. Martino, K. Bender,D. Buckley, D. Stahl. Brock Biology of Microorganisms (Pearson education, USA, 2015) 